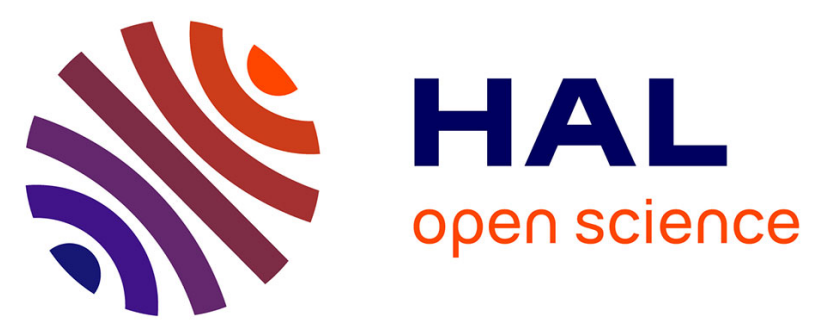

\title{
Risk estimation of uniparental disomy of chromosome 14 or 15 in a fetus with a parent carrying a non-homologous Robertsonian translocation. Should we still perform prenatal diagnosis?
}

Kamran Moradkhani, Laurence Cuisset, Pierre Boisseau, Olivier Pichon, Marine Lebrun, Houda Hamdi-rozé, Marie-Laure Maurin, Nicolas Gruchy, Marie-christine Manca-pellissier, Perrine Malzac, et al.

\section{To cite this version:}

Kamran Moradkhani, Laurence Cuisset, Pierre Boisseau, Olivier Pichon, Marine Lebrun, et al.. Risk estimation of uniparental disomy of chromosome 14 or 15 in a fetus with a parent carrying a nonhomologous Robertsonian translocation. Should we still perform prenatal diagnosis?. Prenatal Diagnosis, 2019, 39 (11), pp.986-992. 10.1002/pd.5518 . hal-02343373

\author{
HAL Id: hal-02343373 \\ https://hal.science/hal-02343373
}

Submitted on 11 Nov 2019

HAL is a multi-disciplinary open access archive for the deposit and dissemination of scientific research documents, whether they are published or not. The documents may come from teaching and research institutions in France or abroad, or from public or private research centers.
L'archive ouverte pluridisciplinaire HAL, est destinée au dépôt et à la diffusion de documents scientifiques de niveau recherche, publiés ou non, émanant des établissements d'enseignement et de recherche français ou étrangers, des laboratoires publics ou privés. 


\section{Risk estimation of uniparental disomy of chromosome 14 or 15 in a fetus with a parent carrying a non-homologous Robertsonian translocation.}

\section{Should we still perform prenatal diagnosis?}

Kamran MORADKHANI 1, Laurence CUISSET 2, Pierre BOISSEAU 1, Olivier PICHON 1, Marine LEBRUN 3, Houda HAMDI-ROZÉ 4, Marie-Laure MAURIN 5, Nicolas GRUCHY 6, Marie-Christine Manca-Pellissier 7, Perrine MALZAC 7, Frédéric BILAN 8, Marie-Pierre AUDREZET 9, Pascale SAUGIER-VEBER ${ }^{10}$, Anne-Laure FAURET-Amsellem ${ }^{11}$, Chantal MISSIRIAN 7, Paul KUENTZ ${ }^{12}$, Gregory EGEA 13, Agnès GUICHET ${ }^{14}$, Isabelle CREVEAUX 15, Renaud TOURAINE ${ }^{3}$, Carole GOUMY 16,17, Nicole JOYÉ 18, Jacques PUECHBERTY 19, Emmanuelle HAQUET 19, Sandra CHANTOT-BASTARAUD ${ }^{20}$, Sébastien SCHMITT' 1, Philippe GOSSET ${ }^{21}$, Bénédicte DUBAN-BEDU 22, Bruno DELOBEL 22, Philippe VAGO 15,16, François VIALARD 23,24, Denise MOLINA GOMES 23,24, Jean-Pierre SIFFROI ${ }^{18}$, Jean-Paul BONNEFONT ${ }^{5}$, Jean-Michel DUPONT ${ }^{25}$, Philippe JONVEAUX ${ }^{26}$, Martine DOCO-FENZY ${ }^{27}$, Damien SANLAVILLE ${ }^{28,29}$, Cédric LE CAIGNEC ${ }^{1}$

1- CHU Nantes, Service de Génétique Médicale, Nantes, France.

2- Laboratory of genetics and molecular biology, Institut Cochin and Cochin Hospital, APHP, Paris Descartes University, Paris

3- Service de Génétique - Laboratoire de biologie moléculaire - CHU Saint-Etienne

4- Department of Molecular Genetics and Genomics, CHU Rennes, Rennes, France.

5- Service d'Histologie, Embryologie, Cytogénétique. Groupe Hospitalier Necker-Enfants Malades

6- Service de Génétique, CHU Caen, Université Caen Normandie

7- Département de génétique médicale, Assistance Publique- Hôpitaux de Marseille

8- Service de génétique, CHU de Poitiers, Poitiers, France

9- Laboratoire de Génétique Moléculaire, CHRU, INSERM U1078, Brest, France

10-Department of Genetics, Normandy Centre for Genomic Medicine and Personalized Medicine, Rouen University Hospital, Rouen, France.

11-Department of Genetics, Robert-Debré Teaching Hospital, Assistance PubliqueHôpitaux de Paris, Paris, France.

12- Génétique Biologique Histologie, Centre Hospitalier Universitaire de Besançon, F-25000, Besançon, France.

13- Laboratoire de biologie médicale GEN-BIO, Clermont-Ferrand, France.

14- Service de Génétique, CHU Angers

15- Laboratoire de biochimie médicale et biologie moléculaire, Centre de Biologie, ClermontFerrand, France

16- Cytogénétique Médicale, CHU Estaing, Clermont-Ferrand, France 
17- Université Clermont Auvergne, INSERM, U1240 Imagerie Moléculaire et Stratégies Théranostiques, Clermont-Ferrand, France

18- Sorbonne Université, INSERM, Physiopathologie des Maladies Génétiques d’Expression Pédiatrique, F-75012 Paris, France

19- Département de Génétique Médicale, Maladies Rares et Médecine Personnalisée, Hôpital Arnaud de Villeneuve, CHU de Montpellier

20- INSERM, Physiopathologie des Maladies Génétiques d'Expression Pédiatrique, F-75012 Paris, France.

21- Laboratoire de diagnostic génétique, Hôpitaux Universitaires de Strasbourg, Strasbourg, France.

22-Centre de Génétique Chromosomique, GH de l'Institut Catholique de Lille - Hopital Saint Vincent de Paul, Lille, France.

23- Unité de Cytoénétique, CHI de Poissy St Germain en Laye, 78300 Poissy, France

24- EA7404-GIG, UFR des Sciences de la Santé Simone Veil, UVSQ, 78180 Montigny le bretonneux, France.

25- Laboratoire de Cytogénétique, HUPC hôpital Cochin, APHP ; Université Paris Descartes, Paris, France.

26- Laboratoire de génétique, CHRU Nancy, Inserm U1256, Université de Lorraine, Nancy, France.

27- Service de Génétique, CHU REIMS, EA3801, UFR de Médecine REIMS, France.

28- Department of Genetics, Lyon University Hospitals, Lyon, France

29-Claude Bernard Lyon I University; Lyon Neuroscience Research Centre, CNRS UMR5292, Inserm U1028, Lyon, France. 


\section{ABSTRACT}

Uniparental disomy (UPD) testing is currently recommended during pregnancy in fetuses carrying a balanced Robertsonian translocation (ROB) involving chromosome 14 or 15, both chromosomes containing imprinted genes. The overall risk that such a fetus presents a UPD has been previously estimated to be around $\sim 0.6-0.8 \%$. However, because UPD are rare events and this estimate has been calculated from a number of studies of limited size, we have reevaluated the risk of UPD in fetuses for whom one of the parents was known to carry a nonhomologous ROB (NHROB). We focused our multicentric study on NHROB involving chromosome 14 and/or 15. A total of 1747 UPD testing were performed in fetuses during pregnancy for the presence of UPD(14) and/or UPD(15). All fetuses were negative except one with a UPD(14) associated to a maternally inherited rob(13;14). Considering these data, the risk of UPD following prenatal diagnosis of an inherited ROB involving chromosome 14 and/or 15 could be estimated to be around $0.06 \%$, far less than the previous estimation. Importantly, the risk of miscarriage following an invasive prenatal sampling is higher than the risk of UPD. Therefore, we do not recommend prenatal testing for UPD(15)mat, UPD(14)mat, UPD(14)pat for these pregnancies and parents should be reassured. Sonographic examination will help detecting the extremely rare fetuses with Prader-Willi, Kagami-Ogata or Temple syndrome. Given the fact that no sonographic features can reliably detect fetuses with Angelman syndrome, a prenatal invasive sampling to test UPD(15)pat could be discussed with future parents.

\section{Keywords:}

Uniparental disomy (UPD), UPD of chromosome 14 and 15, UPD(14), UPD(15), Inherited Robertsonian Translocation, Trisomy rescue, monosomy rescue, Gametic complementation 


\section{Introduction}

Uniparental disomy (UPD) occurs when both copies of a chromosome, or part of a chromosome, are derived from a single parent. UPD is called heterodisomy when a pair of nonidentical chromosomes is inherited from one parent or isodisomy when a single chromosome from one parent is duplicated. UPD may have clinical relevance for several reasons. Isodisomy leads to large blocks of homozygosity, which may lead to the uncovering of recessive alleles. Either isodisomy or heterodisomy can disrupt parent-specific imprinted genes, resulting in imprinting disorders, among them the well-known Prader-Willi (PWS; OMIM 176270) and Angelman (AS; OMIM 105830) syndromes for chromosome 15. PWS is characterized by short stature, obesity, hypogonadism, and learning difficulty. Approximately $70 \%$ of individuals with PWS carry a microdeletion at 15q11q13 of the paternally derived homolog. Most (25\%) of the remaining patients with PWS have maternal UPD(15). AS is characterized by severe learning difficulties, epilepsy and ataxic gait. Approximately $70 \%$ of individuals with AS carry an interstitial microdeletion of the same 15q11q13 region as in PWS, but in this case on the maternally derived homolog. About $2 \%$ of the remaining patients present paternal UPD(15).

Three different mechanisms explain UPD: (i) trisomy rescue (ii) monosomy rescue and (iii) gametic complementation [1]. However, the main mechanism responsible for UPD is trisomy rescue mostly related to advanced maternal age [2]. This is highlighted by the higher proportion of maternal UPD to the etiology of PWS compared to that of paternal UPD to the etiology of AS ( $25 \%$ versus $2 \%$ ). Apart advanced maternal age, any condition predisposing to aneuploid gametes increases the risk for UPD. Therefore, individuals carrying a balanced Robertsonian translocation (ROB) have an increased risk of aneuploid embryos, miscarriages and UPD following trisomy rescue.

UPD testing is currently recommended in fetuses carrying a balanced ROB involving chromosome 14 or 15 [1]. Thus, most of the cytogenetic laboratories follow this recommendation and some of them attempted to estimate the risk of UPD following prenatal diagnosis of a ROB involving chromosome 14 or 15 [3,4,5,6,7,8]. From these combined data, the overall risk that a fetus with a non-homologous ROB (NHROB) presents a UPD has been estimated to be around $\sim 0.6-0.8 \%$ [9]. However, because UPD are rare events and this estimate has been calculated from a number of studies of limited size, we have reevaluated the risk of UPD in fetuses for whom one of the parents was known to carry a NHROB. We focused our multicentric study on NHROB involving chromosome 14 and/or 15, the two chromosomes containing imprinted genes involved in ROB. 


\section{Patients and Methods}

Data were collected from 28 French genetic laboratories, all members of the "Association des Cytogénéticiens de Langue Française (ACLF; the French-Speaking Cytogeneticists Association)" and/or the Association Nationale des Praticiens en Génétique Moléculaire (ANPGM; National Association of Molecular Genetics Practitioners). The current study was set up to gather the results of UPD survey, over more than 10 years, in prenatal period. The study followed the local ethical guidelines of CHU Nantes, France. The study was reviewed and approved by the Board of the ACLF.

The genetic laboratories provided the results of $\operatorname{UPD}(14)$ and $\operatorname{UPD}(15)$ testing in fetuses for whom one of the parents was known to carry a NHROB. Fetal karyotype was obtained from amniotic fluid and/or chorionic villi samples. Eight laboratories also provided the results of UPD testing performed in fetuses with normal karyotype but conceived by a parent carrying a NHROB.

UPD tests were performed using different methods depending on the chromosome involved. UPD(15) tests were carried out using MS-MLPA Probemix (ME028, PraderWilli/Angelman) from MRC Holland according to the manufacturer's protocol or using custom sets of microsatellite genetic markers (short tandem repeats). UPD(14) tests were performed using the Epitect bisulfite kit Qiagen ${ }^{\circledR}$ enabling the study of the methylation status of MEG3 (Maternally Expressed Gene) on chromosomal region 14q32.2 followed by confirmation with microsatellite genetic markers on chromosome 14 for positive cases.

\section{Results}

Twenty-eight genetic laboratories participated to this retrospective study. A total of 1747 UPD diagnoses were performed.

We obtained additional data for 832 fetuses among them 661 inherited the balanced NHROB while $171 \mathrm{had}$ a normal karyotype. Thus, the chromosomes involved in the translocation were obtained for 661 fetuses as well as the sex of its carrier parent (table 1). No significant difference was observed in the sex of the carrier parent (336 translocations were present in the father and 325 in the mother). As expected, the most frequent translocation was the $\operatorname{rob}(13 ; 14)$ (394 fetuses among 661) followed by the rob(14;21) (112 fetuses among 661). The other translocations (i.e. $\operatorname{rob}(14 ; 15) \operatorname{rob}(14 ; 22), \operatorname{rob}(13 ; 15), \operatorname{rob}(15 ; 21)$ and $\operatorname{rob}(15 ; 22))$ were observed in the remaining 115 fetuses. 
Table 1: Type of Robertsonian translocation and parental origin

\begin{tabular}{|c|c|c|}
\hline Fetal NHROB & Paternal & Maternal \\
\hline $\operatorname{rob}(13 ; 14)$ & 205 & 189 \\
$\operatorname{rob}(14 ; 15)$ & 35 & 17 \\
$\operatorname{rob}(14 ; 21)$ & 54 & 58 \\
$\operatorname{rob}(14 ; 22)$ & 7 & 21 \\
$\operatorname{rob}(13 ; 15)$ & 18 & 13 \\
$\operatorname{rob}(15 ; 21)$ & 8 & 11 \\
$\operatorname{rob}(15 ; 22)$ & 9 & 16 \\
Total & 336 & 325 \\
\hline
\end{tabular}

Among the 1747 fetuses diagnosed for UPD, 686 were tested for UPD(15) and 1061 for UPD(14). No fetuses showed UPD(15). Only one fetus out of 1061 showed UPD(14) of maternal origin. The fetal karyotype was $45, \mathrm{XX}, \operatorname{rob}(13 ; 14)(\mathrm{q} 10 ; \mathrm{q} 10)$ and the translocation was inherited from her 28-year-old mother. Intrauterine growth retardation was noted during pregnancy. After genetic counseling the parents decided to continue the pregnancy. A girl was born at 40 weeks of gestation. Birth parameters were less than $10^{\text {th }}$ percentile (weight $2965 \mathrm{~g}$ and length $46 \mathrm{~cm}$ ). The child was not available for postnatal follow up.

Among the 171 fetuses with normal karyotype but conceived by a ROB carrier parent, none of them showed UPD for chromosome 14 or 15.

\section{Discussion}

The concept of UPD was first introduced by Eric Engel in 1980 when he hypothesized that patients might present a genetic disorder caused by the presence of two copies of the same homolog inherited from only one of their parents [10]. As explained in his memories, his paper "slept on a shelf for several years waiting for more evolution in molecular techniques to be able to study the parental origin of chromosomes from their DNA polymorphisms" [11,12] Warburton D. 1988 AJHG 1988;42:215-216). Finally, proof of concept was achieved after publication of a patient with cystic fibrosis [13]. Only one of his parents was carrying a heterozygous pathogenic variant in the CFTR gene, the patient carried the variant in a homozygous state resulting from an isodisomy of chromosome 7 of maternal origin. Afterwards, during the late 1980s and early 1990s, the first patients with PWS and AS caused by maternal and 
paternal UPD(15), respectively, and patients with Temple Syndrome (OMIM 616222) and Kagami-Ogata syndrome (OMIM 608149) caused by maternal and paternal UPD(14), respectively, were reported $[14,15]$. For those cases, the UPD was suspected since the patient was a carrier of a balanced ROB involving either chromosome 15 or 14 inherited from a healthy carrier parent.

After these first descriptions, several teams reported patients with UPD(14) or UPD(15) $[16,17,18,19]$ likely corresponding to the unsolved cases left in drawers for a very long time. Overall, thirty years after proof of concept of UPD, very few cases of UPD(14) and UPD(15) associated to an inherited NHROB involving chromosome 14 or 15 have been reported. Among more than 600 cases of UPD(14) and UPD(15) registered in a regularly updated database, only 31 cases are associated to a NHROB, of which 20 cases are de novo and 11 are inherited (Pr. Thomas Liehr, Jena lab-Germany http://upd-tl.com/upd.html and [20]. Of note, these combined data suggest that the risk of UPD is significantly higher when the translocation is de novo in the fetus than when it is inherited from a carrier parent (twice more frequent). Most of these patients are case reports and cannot be used to estimate the risk of UPD for a fetus conceived by a ROB carrier (table 2).

Table 2: Studies estimating the number of fetuses with UPD and an inherited or a de novo NHROB

\section{Nbr Nbr of UPD cases associated Nbr of UPD cases associated to a de novo fetus to an inherited ROB ROB}

Series

Sensi A. $\quad 160 \quad$ One case of UPD(14)mat, (2004) $\quad \operatorname{rob}(14 ; 22)$ mat

Silverstein $\quad 42$

S. (2002)

Ruggeri A. $\quad 83$

(2004)

Jay AM.

(2001)

Barton DE. 14

(1996)

Kotzot D. $\quad 458$

(2000)

one case of upd(14)mat, $\operatorname{rob}(13 ; 14) \mathrm{dn}$

one case of upd(14)mat, $\operatorname{rob}(14 ; 21) \mathrm{dn}$

one case of upd(14)mat, $\operatorname{rob}(13 ; 14) \mathrm{dn}$

Six cases of UPD

779 One case of UPD associated to an inherited ROB $(0.13 \%)$
9 cases of UPD (UPD risk 1.16\%) 
In 2006, Lisa G. Shaffer combined the published data and estimated the risk of UPD when a balanced NHROB (de novo or inherited) is detected in a fetus to be around $0.6-0.8 \%$ (3 fetuses with UPD among 477 fetuses studied). Two UPD were identified in fetuses carrying a de novo $\mathrm{ROB}$ while one fetus inherited the balanced $\mathrm{ROB}$ from a parent. Therefore, the estimated risk of UPD associated to an inherited ROB is approximately $0.2 \%$ (1/477 fetuses). This risk is likely overestimated since only one negative cohort was included, other negative cohorts might have been unpublished [6]. In our ten years retrospective study involving 28 genetic diagnostic laboratories, $>1500$ fetuses carrying a ROB inherited from a healthy parent were tested during pregnancy for the presence of UPD(14) and/or UPD(15). All fetuses were negative except one with a UPD(14)mat associated to an inherited $\operatorname{rob}(13 ; 14)$. The risk of UPD following prenatal diagnosis of an inherited ROB involving chromosome 14 and/or 15 could be estimated around $0.06 \%$, far less than the previously estimation of $0.6 \%$. Importantly, this estimated risk of $0.06 \%$ is less than the risk of miscarriage following invasive fetal sampling, despite the fact that this estimated risk of miscarriage is still controversial (reevaluated by Akolekar R. (2015)[21]. Until recently, when a parent was carrying a ROB involving chromosomes 13 or 21, an invasive fetal sampling was discussed to exclude a trisomy 13 or 21 . If the ROB involved chromosomes 14 or 15, UPD testing was performed at the same time as karyotyping. Currently, non-invasive prenatal diagnosis (NIPT) is replacing this invasive procedure. Therefore, the only purpose of an invasive procedure would be UPD testing.

UPD following monosomy rescue are rarely observed probably because the embryo does not survive enough to duplicate the autosome and become isodisomic [9]. To the best of our knowledge, only two patients conceived by a ROB carrier were reported postnatally with UPD following monosomy rescue. Recently, Bramswig NC et al. reported a patient with AS caused by UPD(15) and a normal karyotype. The two paternal chromosomes 15 were inherited from his healthy father. The mother was a carrier of a balanced $\operatorname{rob}(14 ; 15)$ [22]. The second patient is a girl presenting with polyhydramnios, short limbs and small thorax during pregnancy [23]. After delivery, a UPD(14)pat was diagnosed explaining the clinical features in this child with a normal karyotype $(46, \mathrm{XX})$. Familial study showed that her mother is carrier of a $\operatorname{rob}(13 ; 14)$. In most laboratories participating in the present study, diagnosis of UPD was carried out if a balanced ROB was detected in the fetus. However, in eight laboratories, all pregnancies conceived with one of the parents carrier of a balanced ROB were tested for UPD regardless of fetal karyotype (carrying the balanced ROB or not). No UPD(14) or UPD(15) was detected in 171 fetuses with normal karyotype which is in agreement with the rare risk of UPD following monosomy rescue. [5] also studied 18 fetuses with a normal karyotype but conceived by a parent carrying a ROB to 
evaluate the risk of monosomy rescue and did not identified any UPD. These results confirm that UPD following a monosomy rescue is extremely rare.

Another mechanism leading to UPD is gametic complementation. This mechanism is extremely rare and not easy to prove unless there is a structural chromosomal anomaly. Up to now, two cases of gametic complementation have been well documented. Cotter PD et al (1997) [24] reported a patient presenting with Kagami-Ogata syndrome (OMIM 608149) due to a UPD(14)pat. The parents of the patient were carriers of two different Robertsonian translocations, the mother with $\operatorname{rob}(14 ; 21)$ and the father with $\operatorname{rob}(13 ; 14)$. These two parental translocations favor the fertilization of a nullisomic gamete for chromosome 14 with a disomic one. Such observation was also observed in another case of Kagami-Ogata syndrome with parents both carriers of chromosomal translocations: the father with $\operatorname{rob}(13 ; 14)$ and mother carrier of a reciprocal translocation $\mathrm{t}(1 ; 14)(\mathrm{q} 32 ; \mathrm{q} 32)$ [25]. When both parents carry a chromosomal translocation involving chromosomes 14 and/or 15, the risk of UPD is highly increased and a prenatal UPD test should be considered.

Our data show that the risk of UPD following prenatal diagnosis in a fetus who inherited ROB involving chromosome 14 and/or 15 is very low. Therefore, if prenatal UPD testing is not done, what is the risk of misdiagnosis of fetal UPD(14) or UPD(15)? During pregnancy, most fetuses with Prader-Willi, Kagami-Ogata or Temple syndrome present abnormal features which can be detected by ultrasound examination. Gross N et al (2015) [26] performed a retrospective study on the prenatal ultrasound records of 106 patients with PWS diagnosed postnatally. In this study, the following ultrasound features were studied: small for gestational age (SGA, $\leq 10$ centile), asymmetrical intrauterine growth, polyhydramnios and breech position. The authors showed that $98 \%$ of the fetuses with PWS presented at least one of these ultrasound features during pregnancy.

In postnatal, patients with Kagami-Ogata syndrome (OMIM 608149) present with feeding difficulties, development delay, intellectual disability and skeletal abnormalities especially a bell-shape thorax and increased coat-hanger angle. In a review, UPD(14)pat was detected in 23/34 patients showing that UPD is a common mechanism leading to the syndrome. In prenatal period, ultrasound signs are almost always observed. The most common fetal ultrasound signs are particular thorax abnormalities small bell-shaped thorax and an abnormal coat-hanger appearance observed in all cases. Polyhydramnios, requiring one or more amnioreduction, is also reported in all cases. In more than $80 \%$ of fetuses, a placentomegaly could also be detected [27]. The association of the these signs is considered a hallmark for UPD(14)pat in prenatal period. 
Thirty-two patients with Temple Syndrome (TS14, OMIM 616222) have been reported [28]. The main features in postnatal period are growth failure, hypotonia, small hands and feet, precocious puberty. Intellectual disability is not frequent. UPD is also a common mechanism leading to the syndrome since $23 / 32$ patients presented with UPD(14)mat. In prenatal period, $90 \%$ of the fetuses present an IUGR (a mean of $-2.2 \mathrm{SD}$ ). A hypoplastic placenta can also be observed.

Taken together, these data show that at least one abnormal sonographic feature is detected in the majority of the fetuses with Prader-Willi, Kagami-Ogata or Temple syndrome [26,27,28 and table 3]. In the context where a parent is a carrier of a ROB involving chromosome 14 or 15 , the detection during pregnancy of a single abnormal ultrasound finding should lead to a prenatal testing for UPD.

Table 3: Prenatal features in fetuses with UPD(14) or UPD(15)

\begin{tabular}{|c|c|c|c|c|}
\hline UPD & $\begin{array}{c}\text { dup(14)pat } \\
\text { Kagami Syndrome }\end{array}$ & $\begin{array}{l}\text { dup(14)mat } \\
\text { Temple } \\
\text { syndrome }\end{array}$ & $\begin{array}{c}\text { dup(15)mat } \\
\text { Prader Willi } \\
\text { Syndrome }\end{array}$ & $\begin{array}{l}\text { dup(15)pat } \\
\text { Angelman } \\
\text { Syndrome }\end{array}$ \\
\hline $\begin{array}{l}\text { Ultrasonographic } \\
\text { signs }\end{array}$ & $\begin{array}{l}\text { Small bell-shaped } \\
\text { thorax with coat- } \\
\text { hanger appearance } \\
\text { of the ribs and } \\
\text { Polyhydramnios (all } \\
\text { cases) }\end{array}$ & $\begin{array}{c}\text { RCIU } \\
\text { (Almost all } \\
\text { cases 97\%) }\end{array}$ & $\begin{array}{c}\text { Polyhydramnios, } \\
\text { Decreased fetal } \\
\text { movement } \\
\text { Breech presentation } \\
\text { Mild prenatal growth } \\
\text { retardation } \\
\text { 2\% of cases present } \\
\text { no ultrasonographic } \\
\text { sign }\end{array}$ & $\begin{array}{c}\text { No } \\
\text { ultrasonographic } \\
\text { sign }\end{array}$ \\
\hline
\end{tabular}

Regarding AS, which can be caused by UPD(15)pat, there are no ultrasound features in an affected fetus which could reliably lead to a suspicion of this syndrome and a prenatal diagnosis. Therefore, a prenatal testing for UPD(15)pat could be proposed (Clinical and genetic aspects of Angelman syndrome, [29]. Nevertheless, to the best of our knowledge, no patients with AS associated to a UPD, diagnosed following a prenatal testing triggered by a parental ROB involving chromosome 15, have been reported. Likewise, no UPD(15)pat has been detected in our series of 686 tests.

In conclusion, we estimate the risk of UPD when a parent is carrier of a NHROB involving chromosome 14 and/or 15 to be about $0.06 \%$, ten times less than the previously published estimation. The risk of miscarriage following an invasive prenatal sampling is higher than the risk of UPD. Therefore, we do not recommend prenatal testing for UPD(15)mat, UPD(14)mat, UPD(14)pat in this context and parent should be reassured. Sonographic examination will help detecting the extremely rare fetuses with Prader-Willi, Kagami-Ogata or Temple syndrome. Given the very low risk of UPD following malsegregation/rescue, a prenatal 
invasive sampling to test UPD(15)pat responsible for Angelman Syndrome could however be discussed with future parents.

\section{$\underline{\text { Consent }}$}

Written informed consent was obtained from the parents.

\section{Acknowledgements}

We thank Dr. Samarth Bhatt for his critical reading of the present manuscript. 


\section{References:}

1- Shaffer LG, Agan N, Goldberg JD et al. American College of Medical Genetics statement of diagnostic testing for uniparental disomy. Genet Med 2001;3:206-11.

2- Claudia Ginsburg, Siv Fokstuen, and Albert Schinzel. The contribution of uniparental disomy to congenital development defects in children born to mothers at advanced childbearing age. AJMG 2000;95:454-460.

3- Sensi A, Cavani S, Villa $\mathrm{N}$ et al. Nonhomologous Robertsonian translocations (NHRTs) and uniparental disomy (UPD) risk: an Italian multicentric prenatal survey. Prenat Diagn 2004;24:64752.

4- Silverstein S, Lerer I, Sagi M et al. Uniparental disomy in fetuses diagnosed with balanced Robertsonian translocations: risk estimate. 2002 Prenat Diagn 2002;22:649-51.

5- Ruggeri A, Dulcetti F, Miozzo M et al. Prenatal search for UPD 14 and UPD 15 in 83 cases of familial and de novo heterologous Robertsonian translocations. Prenat Diagn 2004;24:997-1000.

6- Jay AM, Roberts E, Davies T, et al. Prenatal testing for uniparental disomy (UPD). Prenat Diagn 2001;21:513.

7- Gualandi F, Sensi A, Trabanelli C et al. Prenatal UPD testing survey in Robertsonian translocations. Prenat Diagn 2000;20:465-468.

8- Kosaki K, McGinniss MJ, Veraksa AN, et al. Prader-Willi and Angelman syndromes: diagnosis with a bisulfite-treated methylation-specific PCR method. Am J Med Genet 1997;73:308-13.

9- Shaffer LG. Risk estimates for uniparental disomy following prenatal detection of a nonhomologous Robertsonian translocation. Prenat Diagn 2006;26:303-307.

10- Engel E. A new genetic concept: uniparental disomy and its potential effect, isodisomy. AJMG 1980;6:137-143.

11- Créau-Goldberg N, Gegonne A, Delabar J et al. Maternal origin of a de novo balanced t(21q21q) identified by ets-2 polymorphism. Hum Genet 1987;76:396-398.

12- Warburton D. Uniparental disomy: a rare consequence of the high rate of aneuploidy in human gametes. AJHG 1988;42:215-216.

13- Spence JE, Perciaccante RG, Greig GM et al. Uniparental disomy as a mechanism for human genetic disease. AJHG 1988;42:217-225.

14- Nicholls RD, Knoll JH, Butler MG et al. Genetic imprinting suggested by maternal heterodisomy in nondeletion Prader-Willi syndrome. Nature 1989;342:281-5.

15- Malcolm S, Clayton-Smith J, Nichols M, et al. Uniparental paternal disomy in Angelman's syndrome. Lancet $1991 ; 337: 694-7$.

16- Casamassima AC, Shapiro LR, Wilmot PL, Smith KB. Prader-Willi syndrome and Robertsonian translocations involving chromosome 15. Clin Genet 1991;39:294-7.

17- Smith A, Noel M. A girl with the Prader-Willi syndrome and Robertsonian translocation 45,XX,t( 14;15)(p11;q11) which was present in three normal family members. Hum Genet 1980;55:271-273. 
18- Berry AC, Whittingham AJ, Neville BGR. Chromosome 15 in floppy infants. Arch Dis Child 1982;56:882-885.

19- Smith A, Robson L, Neumann A, et al. Fluorescence in-situ hybridisation and molecular studies used in the characterisation of a Robertsonian translocation (13q15q) in Prader-Willi syndrome. Clin Genet 1993;43:5-8.

20- Liehr T. Cytogenetic contribution to uniparental disomy (UPD). Mol Cytogenet 2010;29:3-8.

21- Akolekar R, Beta J, Picciarelli G, Ogilvie C, et al. Procedure-related risk of miscarriage following amniocentesis and chorionic villus sampling: a systematic review and meta-analysis. Ultrasound Obstet Gynecol. 2015;45:16-26.

22- Bramswig NC, Buiting K, Bechtel N, et al. Angelman Syndrome-Affected Individual with a Numerically Normal Karyotype and Isodisomic Paternal Uniparental Disomy of Chromosome 15 due to Maternal Robertsonian Translocation $(14 ; 15)$ by Monosomy Rescue. Cytogenet Genome Res 2018;18. doi: 10.1159/000490838.

23- Potok O. et al. Paternal uniparental isodisomy for chromosome 14 in a child with normal karyotype, resulting from malsegregation of maternal Robertsonian translocation. European Human Genetic Conference, Vienna, Austria, 2009; P03.147.

24- Cotter PD, Kaffe S, McCurdy LD, et al. Paternal uniparental disomy for chromosome 14: a case report and review. Am J Med Genet 1997;70:74-9.

25- Wang JC, Passage MB, Yen PH, et al. Uniparental heterodisomy for chromosome 14 in a phenotypically abnormal familial balanced 13/14 Robertsonian translocation carrier. Am J Hum Genet 1991;48:1069-74.

26- Gross N, Rabinowitz R, Gross-Tsur V, et al. Prader-Willi syndrome can be diagnosed prenatally. Am J Med Genet A. 2015;167A:80-5.

27- Kagami M, Kurosawa K, Miyazaki O, et al. Comprehensive clinical studies in 34 patients with molecularly defined UPD(14)pat and related conditions. EJHG 2015;23:1488-1498.

28- Kagami M, Nagasaki K, Kosaki R, et al. Temple syndrome: comprehensive molecular and clinical findings in 32 Japanese patients. Genet Med. 2017;19:1356-1366.

29- Williams CA, Driscoll DJ, Dagli AI. Clinical and genetic aspects of Angelman syndrome. Genet Med 2010;12:385-95. 